\title{
Abdominal ultrasound, physical examination, and intraabdominal fluid
}

\author{
Steven Howard Yale ${ }^{1 *}$ (1) , Halil Tekiner $^{2}$ (D), Eileen Scott Yale ${ }^{3}$ (1)
}

To the Editor,

We read with interest the paper by Toledo et al. titled "Abdominal ultrasound augments the medical students' ability to identify free intraabdominal fluid ${ }^{1}$." Identifying a way to teach medical students' bedside abdominal ultrasound is paramount because of its known role in augmenting the physical examination. It has been estimated that at least $500 \mathrm{~mL}$ of intraperitoneal fluid is required for shifting dullness to be detected on physical examination ${ }^{2}$. Presumably, the accuracy for detecting fluid within the abdominal cavity is better when higher volumes are present. However, both ultrasound and computed tomography scans of the abdomen have the ability to detect as little as $100 \mathrm{~mL}$ of intraperitoneal fluid, and thus the physical examination will always be limited for this reason ${ }^{3}$. The questions are whether the physical examination can be taught to improve the examiner's performance and how these bedside maneuvers can be used in combination in order to further enhance the accuracy and reliability in detecting intraperitoneal fluid. The authors identified higher sensitivity, specificity, and accuracy of bedside ultrasound compared with the physical examination in diagnosing intraperitoneal fluid ${ }^{1}$. A prior study comparing these two modalities in first-year medical students found no differences in sensitivity, specificity, and accuracy between these two modalities ${ }^{4}$. We identified several methodological limitations from Toledo et al.'s ${ }^{1}$ study and thus believe that they affected their findings, interpretation, and conclusion.

Free abdominal fluid refers to readably moveable fluid within the intraperitoneal cavity. A small volume may be normally present in otherwise healthy males and females 5 . Thus, the fluid may or may not be pathological, and if the latter is so, it is referred to as ascites. The free intraperitoneal fluid typically follows the contours of intraabdominal organs and conforms to the peritoneal folds. It usually accumulates in dependent regions, and when assuming the supine position it is found in the hepatorenal fossa (Morrison pouch), recto-uterine pouch (pouch of Douglas), and right and left paracolic gutters ${ }^{6}$. Instillation of $2,000 \mathrm{ml}$ of dialysate in the supine position found on a computed tomography abdominal scan confirmed that the majority (30-55\%) of fluid was identified in the pelvis, $15-30 \%$ in the paracolic gutters, $10-20 \%$ in the perisplenic and perihepatic spaces, and $1-3 \%$ in the lesser $\operatorname{sac}^{7}$.

Studies performed by advanced practitioners compared the abdominal physical examination with the abdominal ultrasound and reported wide sensitivities and specificities for flank dullness (57-94\%; 39-69\%), shifting dullness (60-88\%; 56-90\%), and fluid wave $(20-80 \% ; 82-100 \%)^{8-11}$. These findings suggest that no single sign has sufficient sensitivity or specificity to be used alone and would be more useful if used in combination. The best indicators of ascites on physical examination are the presence of a positive fluid wave and shifting dullness. Ascites is unlikely to be found if bulging flanks, flank dullness, and shifting dullness are absent on physical examination.

In Toledo et al.'s study, medical students conducted a physical examination (flank dullness, percussion shifting dullness, and a fluid thrill or wave) and an ultrasound of the abdomen in the right and left upper abdominal quadrants and pelvic cavity $^{1}$. Although the students received didactic and hands-on formal training using abdominal ultrasound, there is no mention of whether this occurred for the physical examination. Furthermore, no information was provided regarding performance on each of these physical examination tests. Shifting dullness is performed by moving the patients to the right or left lateral recumbent position. In doing so, it shifts free intrabdominal fluid to the most dependent position. If the physical

\footnotetext{
'University of Central Florida College of Medicine - Orlando, United States of America.

${ }^{2}$ Erciyes University, Faculty Of Medicine, Department of the History of Medicine and Ethics - Talas, Turkey.

${ }^{3}$ University of Florida, Division of General Internal Medicine - Gainesville, United States of America.

*Corresponding author: steven.yale.md@gmail.com

Conflicts of interest: the authors declare there are no conflicts of interest. Funding: none.

Received on July 24, 2021. Accepted on August 10, 2021.
} 
examination is performed before the ultrasound examination or if the same patient is examined sequentially by different examiners, movement of the patient will affect the location of the fluid making comparison between examiners unreliable. Thus, the interobserver reliability of the test would be completely nullified.

One study in medical students found high interobserver reliability suggesting high concordance in test performance ${ }^{3}$. Toledo et al.'s study adds to the growing body of literature regarding the relative ease of teaching and performing bedside ultrasound $^{1}$. However, further studies are needed to assess the utility of the physical examination using a combination of tests and a more uniformed methodological approach when examining patients with variable amounts of ascites.

\section{AUTHORS' CONTRIBUTIONS}

SHY: Writing - original draft, Writing - review \& editing. HT: Writing - original draft, Writing - review \& editing. ESY: Writing - original draft, Writing - review \& editing.

\section{REFERENCES}

1. Toledo GC, Schreider A, Camilo GB, Colugnati FAB, Fernandes NMS, Bastos MG. Abdominal ultrasound augments the medical students' ability to identify free intraabdominal fluid. Rev Assoc Med Bras. 2021:S0104-42302021005003202. https:// doi.org/10.1590/1806-9282.67.02.20200507

2. Ferguson $\mathrm{CM}$. Inspection, auscultation, palpation, and percussion of the abdomen. In: Walker HK, Hall WD, Hurst JW (eds). Clinical method - the history, physical, and laboratory examinations. 3rd ed. Boston: Butterworths; 1990.

3. Goldberg BB, Clearfield HR, Goodman GA, Morales JO. Ultrasonic determination of ascites. Arch Intern Med. 1973;131(2):217-20. https://doi.org/10.1001/ archinte.1973.00320080053006

4. Arora S, Cheung AC, Tarique U, Agarwal A, Firdouse M, Ailon J. First-year medical students use of ultrasound or physical examination to diagnose hepatomegaly and ascites: a randomized controlled trial. J Ultrasound. 2017;20(3):199-204. https://doi.org/10.1007/s40477017-0261-6

5. Brown SE, Dubbins PA. Detection of free intraperitoneal fluid in healthy young men. J Ultrasound Med. 2012;31(10):152730. https://doi.org/10.7863/jum.2012.31.10.1527
6. Meyers MA. The spread and localization of acute intraperitoneal effusions. Radiology. 1970;95(3):547-54. https://doi. org/10.1148/95.3.547

7. Twardowski ZJ, Tully RJ, Ersoy FF, Dedhia NM. Computerized tomography with and without intraperitoneal contrast for determination of intraabdominal fluid distribution and diagnosis of complications in peritoneal dialysis patients. ASAIO Trans. 1990;36(2):95-103. https://doi.org/10.1097/00002480199004000-00010

8. Chongtham DS, Singh MM, Kalantri SP, Pathak S, Jain AP. Accuracy of clinical manoeuvres in detection of minimal ascites. Indian J Med Sci. 1998;52(11):514-20. PMID: 10218296

9. Simel DL, Halvorsen Júnior RA, Feussner JR. Quantitating bedside diagnosis: clinical evaluation of ascites. J Gen Intern Med. 1988;3(5):423-8. https://doi.org/10.1007/BF02595917

10. Cattau EL Jr, Benjamin SB, Knuff TE, Castell DO. The accuracy of the physical examination in the diagnosis of suspected ascites. JAMA. 1982;247(8):1164-6. https://doi.org/10.1001/ jama.1982.03320330060027

11. Cummings S, Papadakis M, Melnick J, Gooding GA, Tierney Júnior LM. The predictive value of physical examinations for ascites. West J Med. 1985;142(5):633-6. PMID: 3892916 